\title{
Symposium review: Predicting pregnancy loss in dairy cattle*
}

\author{
Alan D. Ealy† ${ }^{\circ}$ and Zachary K. Seekford \\ Department of Animal and Poultry Sciences, Virginia Polytechnic Institute and State University, Blacksburg 24061
}

\begin{abstract}
Several tools exist to diagnose pregnancy in dairy cattle. However, substantial pregnancy loss occurs within the first $60 \mathrm{~d}$ of gestation in cattle, and these losses have a profound adverse economic impact on the dairy and beef cattle industries. Detecting these impending pregnancy losses could offer producers an opportunity to reduce costs associated with this source of reproductive inefficiency. Several of the pregnancy diagnostic tools currently available and new technologies are being examined for their ability to predict pregnancies at risk for failing in early pregnancy. This review provides a synopsis of work undertaken recently to predict pregnancy losses in cattle. Currently, opportunities to predict pregnancy loss include (1) using transrectal ultrasonography to detect loss of the fetal heartbeat, floating debris within the placental fluids, and reductions in fetal size; (2) observing reductions in circulating progesterone concentrations; (3) detecting reductions in concentrations of circulating placental products; namely, pregnancy-associated glycoproteins and microRNAs; and (4) detecting reductions in the early pregnancy-dependent increase in interferon-stimulatory gene expression in peripheral blood leukocytes. An achievable goal may be to identify markers of embryo mortality so that researchers and clinicians can focus their efforts on developing intervention strategies for cows identified to be at risk for pregnancy failure.
\end{abstract} Key words: pregnancy, embryonic loss, placenta, embryo

\section{INTRODUCTION}

Several pregnancy diagnosis tools are available to producers and researchers that allow them to accurately diagnose pregnancy considerably earlier than was possible a few decades ago. These technologies have helped

\footnotetext{
Received June 27, 2019.

Accepted August 22, 2019.

*Presented as part of the Reproduction Symposium: The Etiology of Pregnancy Failure in Cattle - The When and Why at the ADSA Annual Meeting, Cincinnati, Ohio, June 2019.

†Corresponding author: ealy@vt.edu
}

to meet the needs of today's intensive reproductive management practices in dairy cattle. However, refinements of current techniques and development of new techniques are needed to accurately predict viability of the pregnancy so that cows at risk for embryonic and fetal mortality can be identified. If this were possible, then opportunities for developing nutritional and pharmaceutical interventions to limit these embryo failures will be possible. Alternatively, accurate prediction of an impending pregnancy loss would provide producers with the option to terminate the pregnancy so the cow can be rebred, thus reducing the calving interval in these cases.

This short review provides an overview of how to predict pregnancy loss in cattle and the stages of pregnancy at which accurate predictions of pregnancy loss may be possible.

\section{PIVOTAL PERIODS OF PREGNANCY LOSS}

This review is part of the 2019 ADSA Reproduction Symposium focusing on the etiology of pregnancy losses in dairy cattle. The prevalent periods of pregnancy loss were reviewed by others in this symposium, and several extensive reviews have been published on this topic (Santos et al., 2004; Wiltbank et al., 2016). Thus, only a few important points will be made here on this topic.

Approximately 80 to $90 \%$ of cows and heifers inseminated at the proper time relative to ovulation will conceive, but notable losses in pregnancies occur thereafter, with pregnancies failing to reach term in 45 to $65 \%$ of lactating dairy cows, 10 to $30 \%$ of suckled beef cows, and 10 to $20 \%$ of beef and dairy heifers (Santos et al., 2004; Perry et al., 2005; Pohler et al., 2015; Wiltbank et al., 2016; Gatea et al., 2018). The vast majority of these pregnancy failures occur within the first 60 d of gestation. Only 50 to $60 \%$ of fertilized zygotes are viable and have developed to the proper stages of development at d 7 (Pohler et al., 2015; Wiltbank et al., 2016). Also, another 20 to $40 \%$ of these pregnancies will fail between d 8 and 30 of pregnancy (Pohler et al., 2015; Wijma et al., 2016; Wiltbank et al., 2016). Pregnancies surviving to this stage in development experience further losses at a rate of 5 to $20 \%$ after d 28 
(Perry et al., 2005; Wiltbank et al., 2016). Considerable efforts are being made by researchers throughout the United States and globally to describe the causes of these losses to understand the physiological processes in jeopardy of failing so that we can develop strategies that will improve pregnancy retention.

One important facet of understanding the nature of pregnancy losses is to predict, with at least fair accuracy, those pregnancies that are at risk of failing. Several sonographic, hormonal, and molecular approaches exist to diagnose pregnancy in cattle, and many of these may be useful tools for distinguishing between pregnancies that will develop normally to term versus those that will fail during the first 2 mo of gestation. Figure 1 shows some of the technologies that may be used to predict pregnancy losses in cattle.

\section{TRANSRECTAL PALPATION AND ULTRASONOGRAPHY}

\section{Rectal Palpation and Ultrasonography}

The accumulation of fluids within the allantoic and amnionic cavities makes palpation of uterine contents per rectum for pregnancy diagnosis possible at $\mathrm{d} 40$ to 60 after insemination. Experienced technicians may detect pregnancy as early as d 30. Earlier detection for pregnancy can be achieved by transrectal ultrasonography (TRUS), where pregnancy diagnoses and health status of the embryo (via heartbeat detection) can be made as early as d 21 of pregnancy, although TRUS normally is completed on or after d 25 (Kastelic et al., 1989; Beal et al., 1992). Other uses of TRUS include determining fetal sex, detecting twins, and monitoring fetal and placental development (Beal et al., 1992).

It is difficult to diagnose pregnancy loss by rectal palpation, other than by observing notable changes in the volume of placental fluids or marked reductions in fetal size. Rather, monitoring fetal and placental development by TRUS is preferred for diagnosing impending pregnancy losses. Death of the embryo or fetus can be diagnosed by the absence of a heartbeat, placental detachment, reduced placental fluid volumes, or floating structures within these fluids (Lopez-Gatius and Garcia-Ispierto, 2010). Embryo or fetus size and size of ovarian structures have also been associated with pregnancy loss. In cloned fetuses, embryonic and fetal crown-rump length was reduced in pregnancies that aborted by d 90 (Hill et al., 2000; Chavatte-Palmer et al., 2006). The same observation has been made in lactating cows after AI (Kelley et al., 2017), but the predictive ability of using crown-rump length to pre-

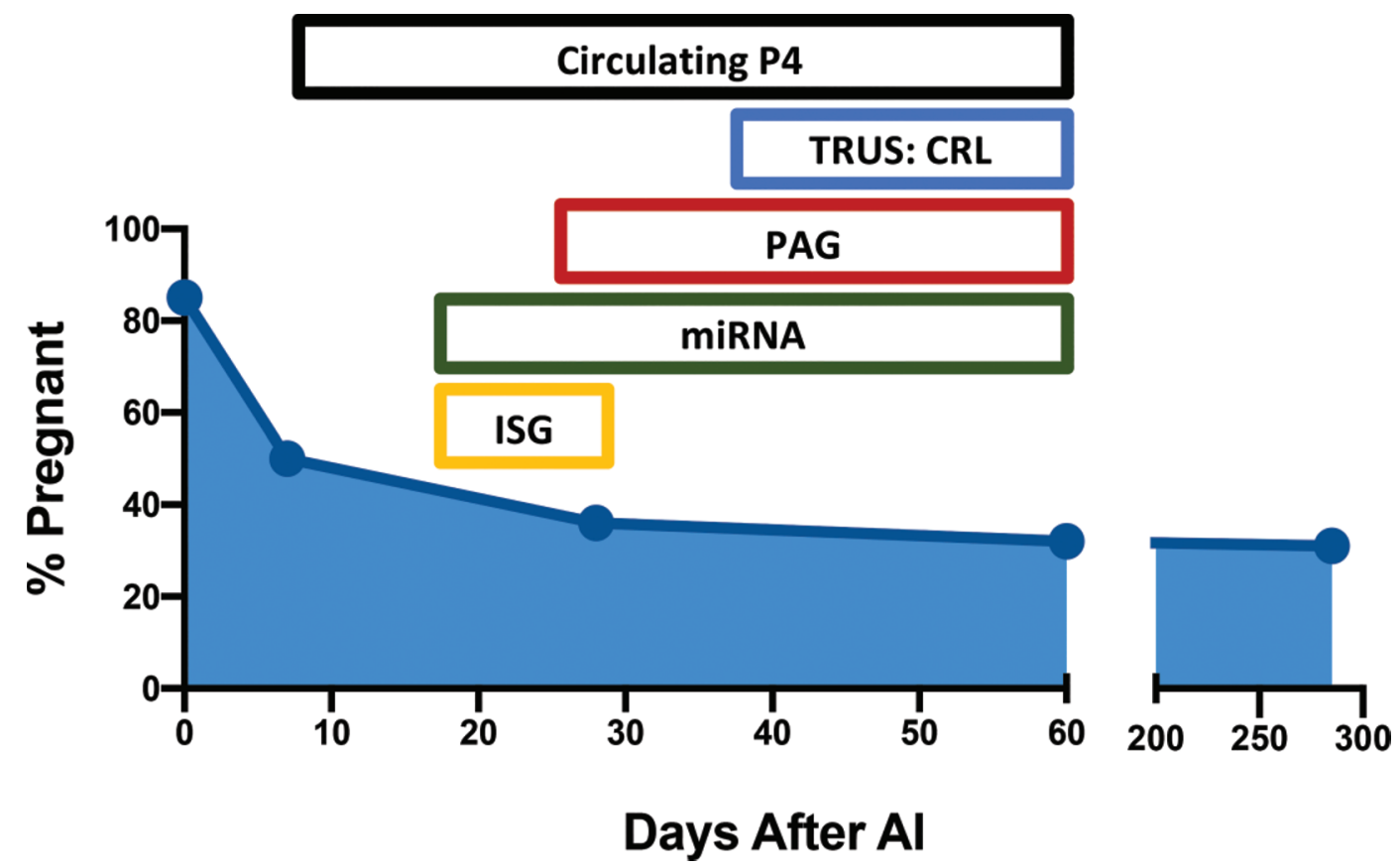

Figure 1. Technologies that may be used to predict pregnancy losses in cattle. Pregnancy loss occurs mainly during the first 2 mo of gestation in cattle. Potential markers of pregnancy loss include (1) reductions in crown-rump length (CRL) as determined by transrectal ultrasonography (TRUS); (2) reductions in circulating pregnancy-associated glycoprotein (PAG) concentrations; (3) alterations in circulating microRNA (miRNA) populations; (4) reduced IFN-stimulator gene (ISG) transcript abundances; and (5) reduced circulating progesterone (P4) concentrations. Future efforts may establish that combining several of these technologies improves the accuracy of detecting pregnancy loss. 
dict pregnancy loss was marginal. Size of the corpus luteum (CL) does not appear to be a good predictor of pregnancy loss (Lopez-Gatius et al., 2002; Starbuck et al., 2004), but size of the peri-ovulatory follicle may predict pregnancy failure. In beef cattle, greater pregnancy losses may occur in cattle with smaller ovulatory follicles, presumably because of reduced estradiol and P4 production (Perry et al., 2005). In lactating dairy cattle, large ovulatory follicles $(\geq 18 \mathrm{~mm})$ are predictive of pregnancy failure between d 30 and 60 (Pereira et al., 2016).

\section{Doppler Ultrasonography}

Doppler ultrasonography is widely used for various purposes to image tissues and organs throughout the body. It is used in cattle to examine ovarian, uterine, and placental blood flow and blood perfusion (Herzog and Bollwein, 2007). It is touted as a useful cow-side predictor of CL activity and an early detector of pregnancy status when the timing of estrus and ovulation are known. There is a positive correlation between CL blood flow and circulating progesterone (P4) concentrations in cyclic and pregnant cows up to d 40 of gestation (Herzog et al., 2010). Blood perfusion rates are also reliable predictors of pregnancy status at d 18 to 24 in both beef and dairy cattle, presumably because these CL survived the maternal recognition of pregnancy period (Siqueira et al., 2013; Pugliesi et al., 2014; Scully et al., 2015). However, we have yet to identify markers of pregnancy loss by using Doppler ultrasonography. Perfusion of the CL at d 19 to 21 or d 34 post-AI is not a good predictor of subsequent pregnancy loss in lactating dairy cows and non-suckled beef cows (Utt et al., 2009; Kelley et al., 2017). Also, no differences in uterine blood flow were detected at d 34 of gestation between lactating dairy cows experiencing pregnancy loss versus maintaining pregnancies to term (Kelley et al., 2017). Perhaps Doppler measurements must be taken closer to the actual time of pregnancy failure to accurately predict impending pregnancy failures.

\section{CIRCULATING PROGESTERONE CONCENTRATIONS}

The decrease in circulating $\mathrm{P} 4$ concentrations that normally occurs at the end each estrous cycle is prevented by the presence of a conceptus (combination of embryonic and extraembryonic tissues). This allows $\mathrm{P} 4$ to continue to regulate uterine function in ways that support pregnancy (Spencer et al., 2016). The divergence in circulating and milk $\mathrm{P} 4$ concentrations between cyclic and pregnancy cattle occurs at d 17 to 24 after insemination (Pohler et al., 2015). Several milk $\mathrm{P} 4$ tests are available commercially, and between 60 and $100 \%$ of cows are correctly diagnosed as pregnant when using these assays at d 20 to 24 after insemination (Pohler et al., 2015). The false pregnancy diagnoses when using this test likely reflect the subset of cyclic cows that exhibit an extended luteal phase (the normal range in estrous cycle length is 17-24 d) and cows that are pregnant but that will undergo embryonic or fetal mortality after d 24 .

Circulating P4 concentrations might also serve as a useful predictor of pregnancy loss. Both the rate of the post-ovulatory increase in circulating $\mathrm{P} 4$ and midluteal P4 concentrations are strongly correlated with embryonic and early conceptus development in cattle (Lonergan, 2011; Spencer et al., 2016). Likewise, lactating dairy cows that underwent pregnancy failure exhibited lower circulating P4 concentrations at d 21 to 34 of pregnancy (Moore et al., 2005; Kelley et al., 2017). However, it has been difficult to define a reliable cutoff point for predicting embryonic mortality. In one study, cows with $<3.76 \mathrm{ng} / \mathrm{mL}$ plasma $\mathrm{P} 4$ were more likely to experience embryonic mortality than cows with greater circulating P4, although most of the cows in the low P4 group did not experience pregnancy loss (Starbuck et al., 2004). However, other work in beef cows found no association between circulating P4 concentrations at d 28 to 30 and pregnancy loss (Pohler et al., 2013). Therefore, it appears that high circulating P4 concentrations are a more useful predictor of pregnancy success than low circulating P4 concentrations are for predicting pregnancy losses.

\section{CIRCULATING PLACENTAL PRODUCTS}

\section{Pregnancy-Associated Glycoproteins}

Circulating pregnancy-associated glycoproteins (PAG) are well-established markers of pregnancy in cattle and other ungulate species (Sasser et al., 1986; Green et al., 2005). Binucleated trophoblast cells within the developing placenta secrete PAG found in the maternal circulation (Wallace et al., 2015). These cells appear when placental attachment with the uterine lumen is initiated at d 18 to 19 of gestation, and sufficient amounts of PAG exist in the maternal circulation to permit immunoassay detection by d 24 to 28 of gestation in cattle (Sasser et al., 1986; Green et al., 2005). Possible functions of PAG include latent growth factor activation, cell adhesion at the chorion-endometrial border, maternal immune system modulation, and luteotrophic abilities (Wallace et al., 2015). A recent report describes PAG as mediators of endometrial gene expression in cattle (Wallace et al., 2019).

Multiple qualitative tests for PAG detection in blood and milk are available commercially. These include Bio- 
PRYN (BioTracking LLC, Moscow, ID), Idexx Bovine Pregnancy Test (Idexx Laboratories Inc., Westbrook, ME), and DG29 Pregnancy Test (Genex Cooperative Inc., Shawano, WI). The predictive ability of PAG for diagnosing pregnancy on or after d 24 to 28 is high (95-98\% accuracy) (Silva et al., 2007; Romano and Larson, 2010; LeBlanc, 2013).

Pregnancy-associated glycoproteins can serve as biomarkers of pregnancy loss in cattle. Multiple studies have observed that circulating PAG concentrations are lower at d 28 to 42 of gestation in cows that subsequently undergo pregnancy loss (Gabor et al., 2007; Mercadante et al., 2013; Gabor et al., 2016; Pohler et al., 2016a,b). Between 25 and $42 \%$ of the cows that underwent embryo mortality were properly diagnosed based on their PAG concentrations at d 30 to 36 (Gabor et al., 2007, 2016; Pohler et al., 2016a). Failure for a greater portion of cows to be diagnosed likely lies in the timing of embryo loss relative to sampling and in other factors that affect circulating PAG concentrations in cattle, such as breed, subspecies, parity, sire, and fetal sex (Wallace et al., 2015). Alternatively, greater predictive ability to detect pregnancy losses may be possible by targeting specific PAG proteins. Numerous PAG are produced by the placenta, and it is possible that some PAG secreted in early pregnancy may be better indicators of pregnancy loss than others. In a recent study, antibodies targeting early-expressed PAG proteins were used to predict pregnancy losses in timed-inseminated cattle between d 30 and 60, whereas other antibody preparations could not predict pregnancy loss (Gatea et al., 2018).

\section{MicroRNA}

Extracellular vesicles (EV) are small (nanometer) structures released by every cell type studied to date (Machtinger et al., 2016). Exosomes (40-100 nm) and microvesicles $(50-1,000 \mathrm{~nm}$ in diameter) are the most common types of EV implicated in controlling various reproductive processes, including capacitation, fertilization, and embryo-endometrium communication (Machtinger et al., 2016; Kurian and Modi, 2019). These EV function by serving as transport vessels for mRNA, microRNA (miRNA), proteins, and various cell signaling regulators. MicroRNA are small, noncoding RNA molecules (18-22 nt in length) that function primarily in RNA silencing (Machtinger et al., 2016; Kurian and Modi, 2019). Various miRNA can be found in EV within biological fluids, including blood, serum, amniotic fluid, urine, and milk. Their packaging within EV permits them to be extracted from bodily fluids and used as biomarkers of tissue and organ physiol- ogy. It is interesting to note that a set of miRNA have been linked with endometrial fertility status in cattle. Sampling endometrium during the estrous cycle before breeding identified 6 miRNA with differential expression that were predictive of pregnancy success in beef cattle (Ponsuksili et al., 2014).

Several miRNA appear capable of serving as bloodbased markers of pregnancy in cattle. Differences in miRNA populations in the maternal circulation between pregnant and cyclic cows may be detected as early as d 8 after insemination (Ioannidis and Donadeu, 2017). At d 16 and 24 post-AI, between 8 and 40 miRNAs are differentially expressed in pregnant versus nonpregnant cows and heifers (Ioannidis and Donadeu, 2016; Pohler et al., 2017; Gebremedhn et al., 2018). Differential miRNA expression has also been noted at d 18 of pregnancy in milk samples from dairy cows (Schanzenbach et al., 2017).

Blood-derived miRNA may also serve as viable biomarkers of pregnancy status in cattle. A recent study identified 32 candidate miRNA that were differentially expressed at d 17 and 24 post-AI in suckled beef cows that underwent early embryonic mortality between d 17 and 30 post-AI compared with cows that maintained pregnancies to term (Pohler et al., 2017). Likewise, abundances of 20 miRNA were altered in cows carrying cloned embryos that aborted by d 90 of gestation versus cloned pregnancies and AI pregnancies that reached term (De Bem et al., 2017). Therefore, based on what has been observed thus far, it seems reasonable to predict that miRNA can be used to diagnose pregnancy status by d 18 of pregnancy. As discussed previously, pregnancy losses occur after d 18, so the predictive ability for diagnosing pregnancies that will be maintained to term is marginal. However, this assessment at d 18 is ideal for identifying open cows so they can be rebred earlier than would be possible by assessing return to estrus or after pregnancy diagnosis on or after d 24 with TRUS or PAG testing. Also, this recent work in placental-derived miRNA suggests that a subset of these miRNA may be useful predictors of embryo and early fetal mortality in cattle.

\section{Early Pregnancy Factor}

Attempts have been made to predict pregnancy status in cattle before d 17 post-AI. Commercial tests are available to evaluate glycoproteins detected in blood or milk within $48 \mathrm{~h}$ of mating in various mammals, including mice, humans, horses, sheep, and cattle (Koch et al., 1983; Morton, 1984). These early pregnancy factor (EPF) and early conception factor assays do not target placental products but rather target oviductal and ovar- 
ian molecules that may contain immunosuppressive and growth-factor activities within the reproductive tract. In cattle, the EPF assay can predict pregnancies as early as d 2 post-insemination. However, recent evaluations of this assay showed that the positive predictive rate (diagnosing pregnancy) and negative predictive rate (diagnosing open) were low at d 6 to 7 or $\mathrm{d} 9$ to 15 after insemination (Pagels et al., 2000; Cordoba et al., 2001). The high rate of early embryonic losses occurring during the first few weeks of gestation likely compromises the accuracy of the test, but one study found that the EPF test was unreliable at d 6 after insemination when pregnancy status was determined by embryo recovery on the same day as the testing (Cordoba et al., 2001). No information could be found about whether EPF testing may predict pregnancy losses.

\section{CIRCULATING IMMUNE CELLS: INTERFERON-STIMULATORY GENES}

The detection of IFN-stimulatory genes (ISG) in peripheral blood leukocytes of cattle is being used as a predictor of conceptus IFN- $\tau$ (IFNT) production during early pregnancy. This protein is the maternal recognition of pregnancy factor in ruminants, and it is produced in large quantities between d 14 and 21 of pregnancy in cattle (Ealy and Yang, 2009). Its primary action is to act locally within the uterus to modify $\mathrm{PGF}_{2 \alpha}$ release and alter uterine gene expression in ways that favor pregnancy maintenance (Ealy and Yang, 2009). Interferon- $\tau$ also acts systemically to affect luteal activity and regulate other cells and tissues (Hansen et al., 2017). Lymphocytes respond to IFNT by heightened expression of several genes commonly associated with IFN responses in various tissues (e.g., MX2, ISG15, and OAS1). These ISG can be detected in circulating lymphocytes by using quantitative reversetranscription PCR at d 17 to 22 of pregnancy in heifers and cows (Gifford et al., 2007; Green et al., 2010). However, because ISG can be stimulated in other physiological states not associated with pregnancy (e.g., pathogen exposure, illness), the lack of ISG response between $\mathrm{d} 17$ and 22 is a better predictor of open status than the presence of an ISG response is for predicting pregnancy (Gifford et al., 2007; Stevenson et al., 2007; Green et al., 2010). It also is interesting that ISG testing can be used in conjunction with PAG testing or TRUS to more accurately predict the timing of early embryonic mortality. Combining these tests would allow us to predict whether cows were pregnant at d 18 to 22 but not at d 28 (i.e., ISG detection but no PAG or embryo) (Wijma et al., 2016).
Little work has been done to evaluate the effectiveness of ISG at predicting pregnancy loss. Reductions in mRNA abundance of MX2 and ISG15 at d 18 to 22 post-AI have been reported in dairy heifers and cows that subsequently lost their pregnancy by d 30 to 60 (Stevenson et al., 2007; Wijma et al., 2016). However, the predictive ability of using ISG for predicting pregnancy loss is low, likely because of the large variability in MX2 responses among cattle. More work is needed to explore the potential of ISG and ISG-miRNA multiplexing for predicting pregnancy losses at d 18 to 22 after insemination.

\section{CONCLUSIONS}

The search for new predictors of pregnancy loss remains elusive for cattle. Loss of fetal heartbeat, noteworthy reductions in fluid volume and fetus size, and floating debris within the placental fluids remain the only definitive markers of impending pregnancy failure. Doppler ultrasonography and circulating PAG concentrations can accurately diagnose pregnancy status by d 24 to 25 of gestation, and ISG analysis in peripheral blood leukocytes and recently identified miRNA allow predictions of pregnancy status by d 17, and perhaps earlier. These technologies can also predict some of the impending pregnancy failures that occur in cattle. Potential markers of pregnancy loss include (1) reductions in crown-rump length, (2) reductions in circulating PAG concentrations, (3) alterations in circulating miRNA populations, (4) reduced ISG transcript abundances, and (5) reduced circulating $\mathrm{P} 4$ concentrations. The most promising means for accurately predicting pregnancy loss probably lies in determining whether a specific subset of PAG or circulating miRNA correlates strongly with pregnancy failure. Alternatively, future work may determine that combining several of these technologies improves the accuracy of detecting pregnancy loss. An achievable goal may not be to identify definitive markers of embryo mortality but rather to identify moderately strong markers of embryonic mortality so that researchers and clinicians can focus their efforts on developing intervention strategies for cows identified to be at risk for pregnancy failure.

\section{ACKNOWLEDGMENTS}

This project was supported by Agriculture and Food Research Initiative Competitive Grants number 201767015-26461 and 2018-67030-28727 from the USDA National Institute of Food and Agriculture (Washington, DC). 


\section{REFERENCES}

Beal, W. E., R. C. Perry, and L. R. Corah. 1992. The use of ultrasound in monitoring reproductive physiology of beef cattle. J. Anim. Sci. 70:924-929.

Chavatte-Palmer, P., N. de Sousa, P. Laigre, S. Camous, A. A. Ponter, J. F. Beckers, and Y. Heyman. 2006. Ultrasound fetal measurements and pregnancy associated glycoprotein secretion in early pregnancy in cattle recipients carrying somatic clones. Theriogenology 66:829-840.

Cordoba, M. C., R. Sartori, and P. M. Fricke. 2001. Assessment of a commercially available early conception factor (ECF) test for determining pregnancy status of dairy cattle. J. Dairy Sci. 84:18841889.

De Bem, T. H. C., J. C. da Silveira, R. V. Sampaio, J. R. Sangalli, M. L. F. Oliveira, R. M. Ferreira, L. A. Silva, F. Perecin, W. A. King, F. V. Meirelles, and E. S. Ramos. 2017. Low levels of exosomalmiRNAs in maternal blood are associated with early pregnancy loss in cloned cattle. Sci. Rep. 7:14319.

Ealy, A. D., and Q. E. Yang. 2009. Control of interferon-tau expression during early pregnancy in ruminants. Am. J. Reprod. Immunol. 61:95-106.

Gabor, G., J. P. Kastelic, Z. Abonyi-Toth, P. Gabor, T. Endrodi, and O. G. Balogh. 2016. Pregnancy loss in dairy cattle: Relationship of ultrasound, blood pregnancy-specific protein $\mathrm{B}$, progesterone and production variables. Reprod. Domest. Anim. 51:467-473.

Gabor, G., F. Toth, L. Ozsvari, Z. Abonyi-Toth, and R. G. Sasser. 2007. Early detection of pregnancy and embryonic loss in dairy cattle by ELISA tests. Reprod. Domest. Anim. 42:633-636.

Gatea, A. O., M. F. Smith, K. G. Pohler, T. Egen, M. H. C. Pereira, J. L. M. Vasconselos, J. C. Lawrence, and J. A. Green. 2018. The ability to predict pregnancy loss in cattle with ELISAs that detect pregnancy- associated glycoproteins is antibody dependent. Theriogenology 108:269-276.

Gebremedhn, S., D. Salilew-Wondim, M. Hoelker, E. Held-Hoelker, C. Neuhoff, E. Tholen, K. Schellander, and D. Tesfaye. 2018. Exploring maternal serum microRNAs during early pregnancy in cattle. Theriogenology 121:196-203.

Gifford, C. A., K. Racicot, D. S. Clark, K. J. Austin, T. R. Hansen, M. C. Lucy, C. J. Davies, and T. L. Ott. 2007. Regulation of interferon-stimulated genes in peripheral blood leukocytes in pregnant and bred, nonpregnant dairy cows. J. Dairy Sci. 90:274-280.

Green, J. A., T. E. Parks, M. P. Avalle, B. P. Telugu, A. L. McLain, A. J. Peterson, W. McMillan, N. Mathialagan, R. R. Hook, S. Xie, and R. M. Roberts. 2005. The establishment of an ELISA for the detection of pregnancy-associated glycoproteins (PAGs) in the serum of pregnant cows and heifers. Theriogenology 63:1481-1503.

Green, J. C., C. S. Okamura, S. E. Poock, and M. C. Lucy. 2010. Measurement of interferon-tau (IFN-tau) stimulated gene expression in blood leukocytes for pregnancy diagnosis within 18-20d after insemination in dairy cattle. Anim. Reprod. Sci. 121:24-33.

Hansen, T. R., L. D. P. Sinedino, and T. E. Spencer. 2017. Paracrine and endocrine actions of interferon tau (IFNT). Reproduction 154:F45-F59.

Herzog, K., and H. Bollwein. 2007. Application of Doppler ultrasonography in cattle reproduction. Zuchthygiene 42(Suppl. 2):51-58.

Herzog, K., M. Brockhan-Ludemann, M. Kaske, N. Beindorff, V. Paul, H. Niemann, and H. Bollwein. 2010. Luteal blood flow is a more appropriate indicator for luteal function during the bovine estrous cycle than luteal size. Theriogenology 73:691-697.

Hill, J. R., R. C. Burghardt, K. Jones, C. R. Long, C. R. Looney, T. Shin, T. E. Spencer, J. A. Thompson, Q. A. Winger, and M. E. Westhusin. 2000. Evidence for placental abnormality as the major cause of mortality in first-trimester somatic cell cloned bovine fetuses. Biol. Reprod. 63:1787-1794.

Ioannidis, J., and F. X. Donadeu. 2016. Circulating miRNA signatures of early pregnancy in cattle. BMC Genomics 17:184.

Ioannidis, J., and F. X. Donadeu. 2017. Changes in circulating microRNA levels can be identified as early as day 8 of pregnancy in cattle. PLoS One 12:e0174892.
Kastelic, J. P., S. Curran, and O. J. Ginther. 1989. Accuracy of ultrasonography for pregnancy diagnosis on days 10 to 22 in heifers. Theriogenology 31:813-820.

Kelley, D. E., K. N. Galvao, C. J. Mortensen, C. A. Risco, and A. D. Ealy. 2017. Using Doppler ultrasonography on day 34 of pregnancy to predict pregnancy loss in lactating dairy cattle. J. Dairy Sci. 100:3266-3271.

Koch, E., H. Morton, and F. Ellendorff. 1983. Early pregnancy factor: Biology and practical application. Br. Vet. J. 139:52-58.

Kurian, N. K., and D. Modi. 2019. Extracellular vesicle mediated embryo-endometrial cross talk during implantation and in pregnancy. J. Assist. Reprod. Genet. 36:189-198.

LeBlanc, S. J. 2013. Short communication: field evaluation of a pregnancy confirmation test using milk samples in dairy cows. J. Dairy Sci. 96:2345-2348.

Lonergan, P. 2011. Influence of progesterone on oocyte quality and embryo development in cows. Theriogenology 76:1594-1601.

Lopez-Gatius, F., and I. Garcia-Ispierto. 2010. Ultrasound and endocrine findings that help to assess the risk of late embryo/early foetal loss by non-infectious cause in dairy cattle. Reprod. Domest. Anim. 45(Suppl. 3):15-24.

Lopez-Gatius, F., P. Santolaria, J. Yaniz, J. Rutllant, and M. LopezBejar. 2002. Factors affecting pregnancy loss from gestation Day 38 to 90 in lactating dairy cows from a single herd. Theriogenology 57:1251-1261.

Machtinger, R., L. C. Laurent, and A. A. Baccarelli. 2016. Extracellular vesicles: Roles in gamete maturation, fertilization and embryo implantation. Hum. Reprod. Update 22:182-193.

Mercadante, P. M., K. M. Waters, V. R. Mercadante, G. C. Lamb, M. A. Elzo, S. E. Johnson, D. O. Rae, J. V. Yelich, and A. D. Ealy. 2013. Subspecies differences in early fetal development and plasma pregnancy-associated glycoprotein concentrations in cattle. J. Anim. Sci. 91:3693-3701.

Moore, D. A., M. W. Overton, R. C. Chebel, M. L. Truscott, and R. H. BonDurant. 2005. Evaluation of factors that affect embryonic loss in dairy cattle. J. Am. Vet. Med. Assoc. 226:1112-1118.

Morton, H. 1984. Early pregnancy factor (EPF): A link between fertilization and immunomodulation. Aust. J. Biol. Sci. 37:393-407.

Pagels, L. A., M. G. Daves, and C. S. Whisnant. 2000. Effectiveness of an early pregnancy test for cows. J. Dairy Sci. 83(Suppl. 1):204. (Abstr)

Pereira, M. H. C., M. C. Wiltbank, and J. L. M. Vasconcelos. 2016. Expression of estrus improves fertility and decreases pregnancy losses in lactating dairy cows that receive artificial insemination or embryo transfer. J. Dairy Sci. 99:2237-2247.

Perry, G. A., M. F. Smith, M. C. Lucy, J. A. Green, T. E. Parks, M. D. MacNeil, A. J. Roberts, and T. W. Geary. 2005. Relationship between follicle size at insemination and pregnancy success. Proc. Natl. Acad. Sci. USA 102:5268-5273.

Pohler, K. G., T. W. Geary, C. L. Johnson, J. A. Atkins, E. M. Jinks, D. C. Busch, J. A. Green, M. D. MacNeil, and M. F. Smith. 2013. Circulating bovine pregnancy associated glycoproteins are associated with late embryonic/fetal survival but not ovulatory follicle size in suckled beef cows. J. Anim. Sci. 91:4158-4167.

Pohler, K. G., J. A. Green, T. W. Geary, R. F. Peres, M. H. Pereira, J. L. Vasconcelos, and M. F. Smith. 2015. Predicting embryo presence and viability. Adv. Anat. Embryol. Cell Biol. 216:253-270.

Pohler, K. G., J. A. Green, L. A. Moley, S. Gunewardena, W. T. Hung, R. R. Payton, X. Hong, L. K. Christenson, T. W. Geary, and M. F. Smith. 2017. Circulating microRNA as candidates for early embryonic viability in cattle. Mol. Reprod. Dev. 84:731-743.

Pohler, K. G., M. H. C. Pereira, F. R. Lopes, J. C. Lawrence, D. H. Keisler, M. F. Smith, J. L. M. Vasconcelos, and J. A. Green. 2016a. Circulating concentrations of bovine pregnancy-associated glycoproteins and late embryonic mortality in lactating dairy herds. J. Dairy Sci. 99:1584-1594.

Pohler, K. G., R. F. G. Peres, J. A. Green, H. Graff, T. Martins, J. L. M. Vasconcelos, and M. F. Smith. 2016b. Use of bovine pregnancy-associated glycoproteins to predict late embryonic mortality in postpartum Nelore beef cows. Theriogenology 85:1652-1659. 
Ponsuksili, S., D. Tesfaye, K. Schellander, M. Hoelker, F. Hadlich, M. Schwerin, and K. Wimmers. 2014. Differential expression of miRNAs and their target mRNAs in endometria prior to maternal recognition of pregnancy associates with endometrial receptivity for in vivo- and in vitro-produced bovine embryos. Biol. Reprod. 91:135.

Pugliesi, G., B. T. Miagawa, Y. N. Paiva, M. R. Franca, L. A. Silva, and M. Binelli. 2014. Conceptus-induced changes in the gene expression of blood immune cells and the ultrasound-accessed luteal function in beef cattle: How early can we detect pregnancy? Biol. Reprod. 91:95.

Romano, J. E., and J. E. Larson. 2010. Accuracy of pregnancy specific protein-B test for early pregnancy diagnosis in dairy cattle. Theriogenology 74:932-939.

Santos, J. E., W. W. Thatcher, R. C. Chebel, R. L. Cerri, and K. N. Galvao. 2004. The effect of embryonic death rates in cattle on the efficacy of estrus synchronization programs. Anim. Reprod. Sci. 82-83:513-535.

Sasser, R. G., C. A. Ruder, K. A. Ivani, J. E. Butler, and W. C. Hamilton. 1986. Detection of pregnancy by radioimmunoassay of a novel pregnancy-specific protein in serum of cows and a profile of serum concentrations during gestation. Biol. Reprod. 35:936-942.

Schanzenbach, C. I., B. Kirchner, S. E. Ulbrich, and M. W. Pfaffl. 2017. Can milk cell or skim milk miRNAs be used as biomarkers for early pregnancy detection in cattle? PLoS One 12:e0172220.

Scully, S., A. C. Evans, F. Carter, P. Duffy, P. Lonergan, and M. A. Crowe. 2015. Ultrasound monitoring of blood flow and echotexture of the corpus luteum and uterus during early pregnancy of beef heifers. Theriogenology 83:449-458.

Silva, E., R. A. Sterry, D. Kolb, N. Mathialagan, M. F. McGrath, J. M. Ballam, and P. M. Fricke. 2007. Accuracy of a pregnancyassociated glycoprotein ELISA to determine pregnancy status of lactating dairy cows twenty-seven days after timed artificial insemination. J. Dairy Sci. 90:4612-4622.

Siqueira, L. G., V. S. Areas, A. M. Ghetti, J. F. Fonseca, M. P. Palhao, C. A. Fernandes, and J. H. Viana. 2013. Color Doppler flow imaging for the early detection of nonpregnant cattle at 20 days after timed artificial insemination. J. Dairy Sci. 96:6461-6472.
Spencer, T. E., N. Forde, and P. Lonergan. 2016. The role of progesterone and conceptus-derived factors in uterine biology during early pregnancy in ruminants. J. Dairy Sci. 99:5941-5950.

Starbuck, M. J., R. A. Dailey, and E. K. Inskeep. 2004. Factors affecting retention of early pregnancy in dairy cattle. Anim. Reprod. Sci. 84:27-39.

Stevenson, J. L., J. C. Dalton, T. L. Ott, K. E. Racicot, and R. C. Chebel. 2007. Correlation between reproductive status and steadystate messenger ribonucleic acid levels of the Myxovirus resistance gene, MX2, in peripheral blood leukocytes of dairy heifers. J. Anim. Sci. 85:2163-2172.

Utt, M. D., G. L. Johnson 3rd, and W. E. Beal. 2009. The evaluation of corpus luteum blood flow using color-flow Doppler ultrasound for early pregnancy diagnosis in bovine embryo recipients. Theriogenology 71:707-715.

Wallace, R. M., M. L. Hart, T. E. Egen, A. Schmelzle, M. F. Smith K. G. Pohler, and J. A. Green. 2019. Bovine pregnancy associated glycoproteins can alter selected transcripts in bovine endometrial explants. Theriogenology 131:123-132.

Wallace, R. M., K. G. Pohler, M. F. Smith, and J. A. Green. 2015. Placental PAGs: Gene origins, expression patterns, and use as markers of pregnancy. Reproduction 149:R115-R126.

Wijma, R., M. L. Stangaferro, M. M. Kamat, S. Vasudevan, T. L. Ott, and J. O. Giordano. 2016. Embryo mortality around the period of maintenance of the corpus luteum causes alterations to the ovarian function of lactating dairy cows. Biol. Reprod. 95:112.

Wiltbank, M. C., G. M. Baez, A. Garcia-Guerra, M. Z. Toledo, P. L. Monteiro, L. F. Melo, J. C. Ochoa, J. E. Santos, and R. Sartori. 2016. Pivotal periods for pregnancy loss during the first trimester of gestation in lactating dairy cows. Theriogenology 86:239-253.

\section{ORCIDS}

Alan D. Ealy (ํ) https://orcid.org/0000-0002-8507-6578 